\title{
Modelling Ozone Disinfection Process for Creating Covid-19 Secure Spaces
}

\begin{tabular}{|r|l|}
\hline Journal: & International Journal of Numerical Methods for Heat and Fluid Flow \\
\hline Manuscript ID & HFF-12-2020-0797.R1 \\
\hline Manuscript Type: & Research Article \\
\hline Keywords: & $\begin{array}{l}\text { Ozone disinfection, COVID-19, Ozone decay rate, Concentration } \\
\text { distribution, Unsteady Reynolds Average Navier-Stokes, Scalar transport } \\
\text { equation }\end{array}$ \\
\hline
\end{tabular}

\section{SCHOLARONE Manuscripts}




\title{
Modelling Ozone Disinfection Process for Creating Covid-19 Secure Spaces
}

\begin{abstract}
Purpose

A novel modelling approach is proposed to study ozone distribution and destruction in indoor spaces. The level of ozone gas concentration in the air, confined within an indoor space during an ozone-based disinfection process, is analysed. The main purpose of this work is to investigate how ozone is distributed in time within an enclosed space.
\end{abstract}

\section{Design/methodology/approach}

A computational methodology for predicting the space and time dependent ozone concentration within the room across the consecutive steps of the disinfection process (generation, dwelling and destruction modes) is proposed. The emission and removal of ozone from the air volume are possible by means of a generator located in the middle of the room. This model also accounts for ozone reactions and decay kinetics, and gravity effect on the air.

\section{Finding}

This work is validated against experimental measurements at different locations in the room during the disinfection cycle. The numerical results are in good agreement with the experimental data. This comparison proves that the presented methodology is able to provide accurate predictions of the time evolution of ozone concentration at different locations of the enclosed space.

\section{Originality/value}

This study introduces a novel computational methodology describing solute transport by turbulent flow for predicting the level of ozone concentration within a closed room during a Covid-19 disinfection process. A parametric study is carried out to evaluate the impact of system settings on the time variation of ozone concentration within the space considered.

Keywords: Ozone disinfection, Covid-19, Ozone decay rate, Concentration distribution, Unsteady Reynolds Average Navier-Stokes, Scalar transport equation 


\section{Introduction}

The Covid-19 outbreak has increased awareness of transmission mechanisms of respiratory diseases, especially in indoor environments. Respiratory viruses spread via direct or indirect contact, droplet and aerosol transmission. Evidence [1, 2] suggests that the virus is quickly released during exhalation, talking, and coughing in microdroplets small enough to remain aloft in the air and on surfaces for days, exposing the surrounding people to high infection risk. Therefore, there is an urgent need for a reliable and efficient disinfection method to decontaminate these high-risk areas. The Covid-19 pandemic has boosted the number of studies on ozone disinfection methods for indoor spaces 3. Ozone is a powerful oxidiser, and an ideal disinfectant, which is effective in killing a wide variety of bacteria and viruses [4, 5]. However, human exposure to ozone can be the cause of several health problems, including coughing, breathing difficulty, and lung damage [6]. Thus, safety considerations should be given full review, i.e., all traces of ozone should be eliminated from indoor space before human occupation. While several experimental works have been carried out to understand the safety and efficacy of ozone as a decontaminator, it is also extremely important defining reliable modelling methodologies for making predictions and optimising the cleaning process. Thus, in the present work, we use computational fluid dynamics (CFD) modelling for analysing the ozone concentration distribution in indoor environments.

In the last decades, evaluation of fluid dynamics patterns in indoor environment environments has been an area under intense investigation [7 9 ]. Likewise, the analysis of how pollution and biological agents can spread within an indoor environment has received continuous attention from the research community [10 12]. Combining such studies to understand the ozone generation, spread and destruction using CFD may provide a better understanding of decontamination issues and allow us to optimise this process. Through the present work, the ozone distribution is modelled in the room air volume and evaluated at each stage of an ozone-based disinfection cycle. Furthermore, by considering such time-frame, we characterise the ozone residence time. This is a key information for assessing the health and the safety conditions associated with the disinfection process [13, 14]. Under normal conditions, the half-life of ozone in indoors is between 7 and $30 \mathrm{~min}$ and is determined primarily by surface removal and air exchange [15] 17]. However, for inferring the ozone lifespan in a complex environment characterized by continuously-changing flow conditions, a high fidelity modelling approach is required.

This study aims to introduce a novel computational methodology able to accurately predict, for a given generator setting, how ozone is distributed in time within an enclosed space considered. Furthermore, this methodology is employed for identifying the optimal time required for effectively 
disinfecting a room by considering various ozone production rates and destruction rates. This paper is organised as follows: Section 2 provides the details on the adopted computational methodology. The description of the problem considered, and the associated experimental setup is reported in Section 3. This is followed by Section 4 in which the results are reported. In the last section, the significant findings of the study are summarised, and recommendations for future studies are made.

\section{Modelling Method}

The forced air circulation within a room may be described by employing turbulent incompressible flow equations, whilst the distribution of ozone concentration in the air may be modelled via the convection-diffusion equation. These equations and their solution method are briefly summarised in this section.

\subsection{Air flow}

The incompressible Navier-Stokes equations, governing time averaged turbulent flow, in dimensional form consists respectively of the mass conservation and the momentum conservation equations, i.e,

$$
\begin{aligned}
\nabla \boldsymbol{v} & =0 \\
\text { and } & \\
\rho \frac{\partial \boldsymbol{v}}{\partial t} & =-\rho(\boldsymbol{v} \nabla) \boldsymbol{v}-\nabla p+(\nu+\hat{\nu}) \nabla^{2} \boldsymbol{v}+\boldsymbol{F}
\end{aligned}
$$

where $\rho$ is the air density, $\boldsymbol{v}$ is the velocity, $p$ is the pressure, $\nu$ is the kinematic viscosity and $\hat{\nu}$ is the turbulent eddy viscosity. Buoyancy-driven mass convection along the vertical direction is generated by the density difference, which is induced by the concentration gradient $C-C_{\infty}$, in which $C_{\infty}$ is the reference concentration (assumed to be 0 in this study) [18. $\boldsymbol{F}$ is a source term formulated to account for buoyancy:

$$
\boldsymbol{F}=\mathrm{g} \beta_{\mathrm{c}}\left(C-C_{\infty}\right) \hat{\boldsymbol{y}}
$$

in which $\hat{\boldsymbol{y}}$ is the unit vector in the vertical direction, $\mathrm{g}$ is the acceleration due to gravity $\left(9.81 \mathrm{~m} / \mathrm{s}^{2}\right), \beta_{c}$ is the coefficient of solutal expansion, assumed to be of order $\mathrm{O}\left(10^{-3}\right)$.

\subsection{Turbulence}

The one equation Spalart-Allmaras (SA) model is employed here for calculating the turbulent eddy viscosity [19 21]. The SA model employs a 
single scalar equation and several constants to model turbulence. The scalar equation is:

$$
\begin{gathered}
\frac{\partial \hat{\nu}}{\partial t}+\frac{\partial u_{j} \hat{\nu}}{\partial x_{j}}=c_{b 1} \hat{S} \hat{\nu}+\frac{1}{\sigma}\left[\frac{\partial}{\partial x_{i}}(\nu+\hat{\nu}) \frac{\partial \hat{\nu}}{\partial x_{i}}+c_{b 2}\left(\frac{\partial \hat{\nu}}{\partial x_{i}}\right)^{2}\right]-c_{w 1} f_{w}\left[\frac{\hat{\nu}}{y}\right]^{2} \\
\text { where } \hat{S}=S+\left(\hat{\nu} / k^{2} y^{2}\right) f_{v 2} \\
f_{v 2}=1-X /\left(1+X f_{v 1}\right)
\end{gathered}
$$

In Equation $5 S$ is the magnitude of vorticity. The eddy viscosity is calculated as:

$$
\nu_{t}=\hat{\nu} f_{v 1}
$$

where,

$$
f_{v 1}=X^{3} /\left(X^{3}+c_{v 1}^{3}\right)
$$

and

$$
X=\hat{\nu} / \nu
$$

The parameter $f_{w}$ is given as:

$$
f_{w}=g\left[\frac{1+c_{w 3}^{6}}{g^{6}+c_{w 3}^{3}}\right]^{1 / 6}
$$

where,

$$
g=r+c_{w 2}\left(r^{6}-r\right)
$$

and

$$
r=\frac{\hat{\nu}}{\hat{S} k^{2} y^{2}} .
$$

The constants are $c_{b 1}=0.1355, \sigma=2 / 3, c_{b 2}=0.622, k=0.41, c_{w 1}=$ $c_{b 1} / k^{2}+\left(1+c_{b 2}\right) / \sigma, c_{w 2}=0.3, c_{w 3}=2$ and $c_{v 1}=7.1$. 


\subsection{Ozone Transport}

The turbulent convection-diffusion equation for evaluating the ozone concentration in space and time may be written as:

$$
\rho \frac{\partial C}{\partial t}=-\rho(\boldsymbol{v} \nabla) C+\rho\left[\frac{\nu}{S c}+\frac{\hat{\nu}}{S c_{t}}\right] \nabla^{2} C+[S-k C],
$$

where $C$ is the ozone volumetric concentration in the air, $S$ is the ozone source, $S c$ and $S c_{t}$ are the Schmidt numbers (assume to be unity) and $k$ is the ozone decay and reaction coefficient. Here it is assumed that the natural ozone decay follows a kinetics represented by a first-order reaction, characterised by the decay constant $k$. The same assumption is made for ozone destruction occurring on the selective surfaces of the built-in ozone destructor, which is part of the ozone system, and this latter effect is included by simply using an appropriate high value of the decay constant $k$ (for the nodes on the surface). It is worth mentioning that whilst the natural decay is a volumetric effect, the destruction occurs only on the surface of the generator when the destruction mode is active.

Computer simulations are performed with a CFD solver based on the finite volume method using a Cell-Centered formulation [22, 23]. The flow distribution in space obtained by solving Equations 1, 2 and 4 are coupled with the concentration distribution of ozone obtained by solving Equation 13. The concentration calculations follow the following consecutive steps: i) ozone generation via source term and concentration distribution in air, ii) dwell time where both ozone generation and destruction are off and iii) ozone destruction, dominated by ozone reactions occurring at the surface of the catalytic ozone destructor, which is integrated in the ozone system. More details about how to model these effects are reported in the following section.

\section{Problem specification}

In this work, an ozone system is placed at the middle of a $47 \mathrm{~m}^{3}$ room $4.0 \mathrm{~m}$ by $4.3 \mathrm{~m}$, and $2.7 \mathrm{~m}$ high. The generator includes the ozone generation system, the destructor, and a fan to blow air; all are integrated in one unit (Figure 1). A mechanical gate is used to divert the direction of air flow from vertical, during ozone generation, to horizontal, during ozone decay. The ozone system uses a catalytic destructor to convert ozone back to oxygen once the sterilisation mode is completed to make the room safe for occupation again. Each of these modes uses a shared inlet to the device but employ different outlet (Figure 1). In generation mode, the air flow rate is $335 \mathrm{~m}^{3} / \mathrm{h}$ induced by a fan pressure rise of $75 \mathrm{~Pa}$ from the inlet $\left(0.028 \mathrm{~m}^{2}\right)$, to the ozone generation outlet $\left(0.0158 \mathrm{~m}^{2}\right)$ of the device. The ozone generation rate is $7 \mathrm{~g} / \mathrm{h}$. 

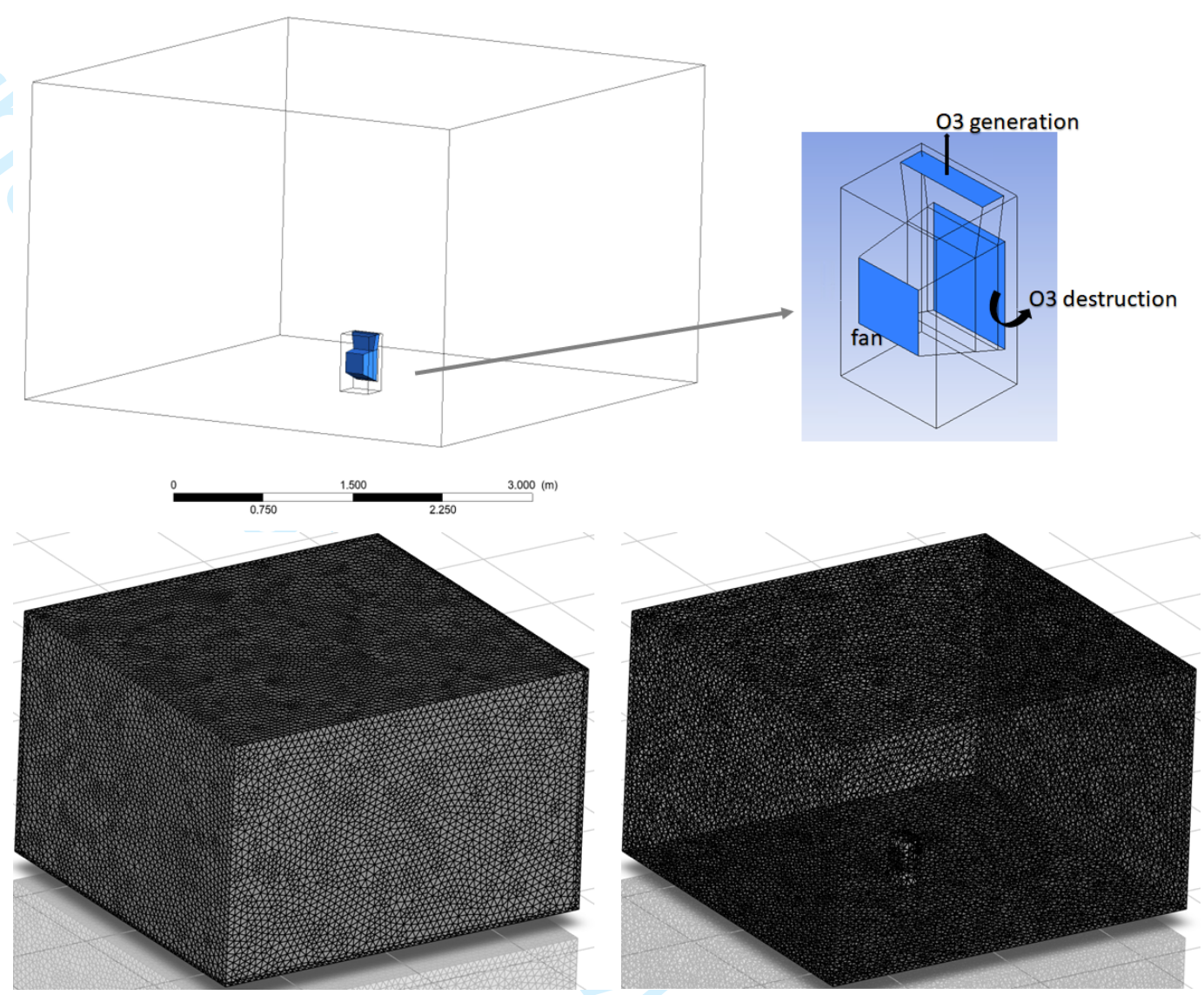

Figure 1: Schematic of model room with zoomed ozone generator and corresponding mesh $(1,139,951$ cells $)$ with the front faces transparent.

In destruction mode, the air flow and ozone destruction rates are $295 \mathrm{~m}^{3} / \mathrm{h}$ induced by a fan pressure rise of $10 \mathrm{~Pa}$ from the inlet $\left(0.028 \mathrm{~m}^{2}\right)$ to the ozone destruction outlet $\left(0.054 \mathrm{~m}^{2}\right)$ of the device. The ozone decay is linked to concentration with a decay constant $k=0.1 \mathrm{~min}^{-1}$. The ozone diffusion coefficient in Equation 13 is $D=3.1116 \cdot 10^{-5} \mathrm{~kg} \mathrm{~m}^{-1} \mathrm{~s}^{-1}$.

The sterilisation cycle modelled consists of three steps. The first is ozone generation and circulation. The second step is a dwell time where ozone is neither generated nor destroyed, but the fan is maintained in generation regime to circulate air. In the final step, the ozone destruction mode is enabled. Several time sequences are tested and explained in the validation section.

\subsection{CFD Solver}

The simulations were carried out using Ansys Fluent on 40 processors with the Intel MPI. The simulations use a scalar transport model for ozone, 
rather than a multi-phase approach which enables the use of the pressurecoupled algorithm. In the spatial domain, gradients are discretised using the cell-based least square algorithm. A second order discretisation is used for the pressure field, and a second order upwind scheme is used for momentum equation. Turbulent viscosity and ozone concentration are both discretised with a first order upwind scheme. The time stepping is done using a first order implicit scheme. A fixed time step of $0.1 \mathrm{~s}$ was employed, whilst the mesh used to represent the system's geometry consists of 1,139,951 cells. Since interest here is ozone concentration, not derivatives, further refinement did not introduce any significant change in concentration distribution

\subsection{Experimental setup}

A Duo20 ozone generator (Advanced Ozone Products, UK) was used to ozonate an empty room $(4.0 \mathrm{~m} \times 4.3 \mathrm{~m} \times 2.7 \mathrm{~m})$. The Duo20 was placed in the centre of the room (on the floor) and set for a 15 min ozone cycle ( $3 \mathrm{~min}$ of ozone generation time, 2 min dwell time and $10 \mathrm{~min}$ ozone destruction time). Ozone concentration was then measured using a six-channel BMT 932 ozone monitor (BMT Messtechnik, Germany). The BMT 932 ozone monitor is able to monitor ozone concentration through 5 channels placed within the room (Channel 6 was placed outside the room for safety purposes) by measuring the UV absorbance at $254 \mathrm{~nm}$. Samples were collected using $3 \mathrm{~m}$ length FEP tubes fixed at different points of the room. The 3-D space coordinates of each point from a reference point were measured using a laser distance measuring meter. The ozone monitor measured ozone concentration at each channel in a sequence mode. The cycle time was $20 \mathrm{~s}$ per sample channel and the room conditions were $1 \mathrm{~atm}$ and $20^{\circ} \mathrm{C}$. Note that, the production rate as determined by the measurements obtained from the channels are found to be around $7 \mathrm{~g} / \mathrm{h}$.

\section{Results and Discussion}

\subsection{Comparison with experimental data}

Here the simulation results are compared against the experimental data recorded at four different locations (coordinates, in metres):

- Channel 1 - Back right corner (floor) $(3.937,4.296,0)$;

- Channel 2 - Wall (1.091, 4.356, 0.959);

- Channel 3 - Front left corner (floor) $(0.04,0.04,0)$

- Channel 4 - On light fixture $(2.356,3.214,2.210)$. 
In Figure 2, three different simulated ozone concentration profiles are displayed for each sensor location, as well as the experimental results: one case presenting $5 \mathrm{~min}$ generation time (no dwell time, i.e. ozone generation off and destruction off), second one with 4 min generation time ( 1 min dwell time), and third one with 3 min generation time (2 min dwell time). The destruction time of all the simulations is conducted for $10 \mathrm{~min}$. According to the manufacturer, the generation time and dwell time are supposed to be $3 \mathrm{~min}$ and $2 \mathrm{~min}$, respectively. However, the real duration of the dwell time is uncertain and potentially affected by different factors, as suggested by the numerical results presented in Figure 2. Thus, 5 min generation without dwell time appears to be a reasonable assumption. The uncertainty arises due to the mechanisms of ozone generation, whereby a sudden shutdown of production is not feasible and thus the device may effectively carry on venting out ozone during the circulation dwell time. This motivated the parametric analysis on generation times and production rates presented in the next sections.

The general trends of the results shown in Figure 2 indicate that at all sensor locations, the ozone concentration inside the room rises rapidly, and then it suddenly drops once the ozone generator is off. For instance, the experimental measurement at back right corner of the room (Channel 1) shows a maximum level of ozone concentration of $10.56 \mathrm{mg} / \mathrm{m}^{3}$ after around $4.4 \mathrm{~min}$ and a lower value of $3.48 \mathrm{mg} / \mathrm{m}^{3}$ (almost 3 times drop compared to the maximum value) at $t=14.97 \mathrm{~min}$, see Figure 2 a. The CFD counterpart shows a maximum level of ozone concentration of $9.32 \mathrm{mg} / \mathrm{m}^{3}$ at $t=5 \mathrm{~min}$ for the $5 \mathrm{~min}$ generation time (no dwell time) scenario, whilst the maximum level of ozone concentration with 4 min generation time (1 $\mathrm{min}$ dwell time) and $3 \mathrm{~min}$ generation time ( $2 \mathrm{~min}$ dwell time) are $8.22 \mathrm{mg} / \mathrm{m}^{3}$ and $6.94 \mathrm{mg} / \mathrm{m}^{3}$, respectively. In addition, the time evolution of the experimentally recorded ozone concentration at Channel 2 (wall, Figure $2 \mathrm{~b}$ ) and Channel 3 (front left corner of the room, Figure 2k) are in good agreement with the numerical results corresponding to a generation time of $5 \mathrm{~min}$ (no dwell time). However, the CFD results corresponding to 4 and 3 min of generation time underestimate the concentration measured at Channel 2 and Channel 3. A similar pattern is also observed for the data corresponding to Channel 4 (see Figure 2d).

It is important to report that, in our experiment, an average ozone concentration value of around $0.26 \mathrm{mg} / \mathrm{m}^{3}$ is recorded by Channels $1-4$ at $t=80 \mathrm{~min}$. This value drops to $0.16 \mathrm{mg} / \mathrm{m}^{3}$ at $t=85 \mathrm{~min}$. This is in line with the guidelines provided by the National Institute for Occupational Safety and Health (NIOSH), which has recently set 24.

Furthermore, transient solutions of ozone concentration distribution fields are presented in Figure 3 for the generation time over the first $3 \mathrm{~min}$, and subsequent dwell time of $2 \mathrm{~min}$. The sudden sharp drop in ozone concentration is evident at the start of the dwell time (from $t=3 \mathrm{~min}$ ). This is also 


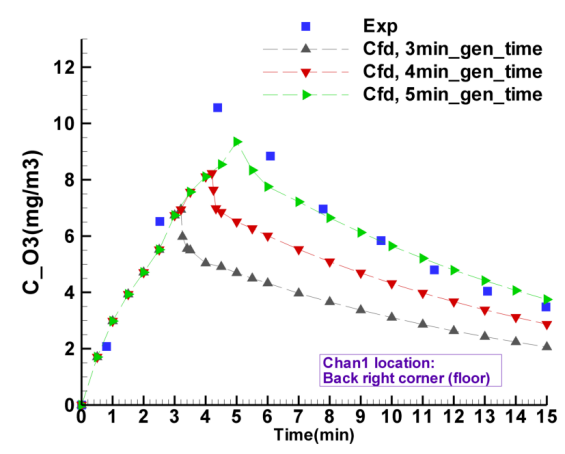

(a)

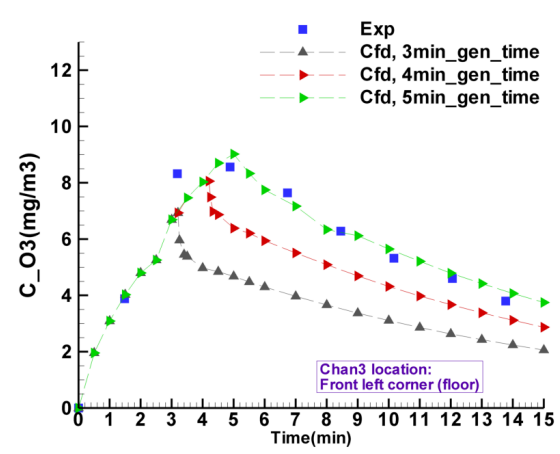

(c)

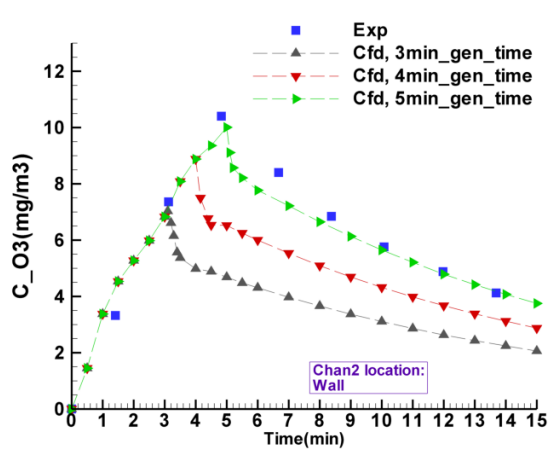

(b)

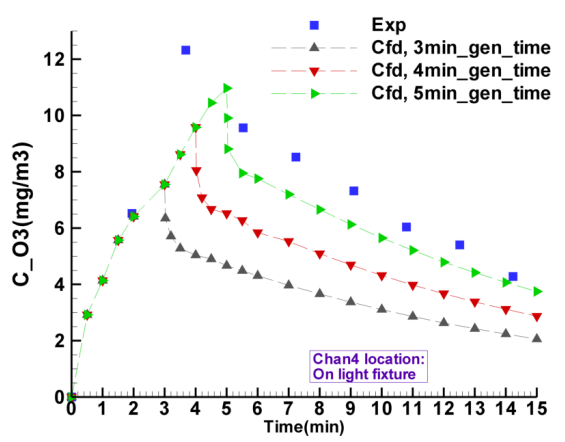

(d)

Figure 2: Comparison between experimental data against CFD results at different locations with different ozone generation times. O3 production rate: $7 \mathrm{~g} / \mathrm{h}$.

evident in Figure 2 for the 3 min generation time case. It is reasonable that at the end of the generation phase higher concentrations are present along the ceiling, wall and floor. This is quickly homogenised in the ventilated dwell phase, resulting in a concentration drop along the walls, where sensors are located. This causes the sharp drop at the end of the ozone production phase. Sensor 3 reports lower concentrations, correctly reproduced in simulations, due to its corner location receiving limited ventilation.

The use of nominal production rates and flow rates from the device in the CFD calculations shows a concentration rise at the locations of measurement and agrees well with the experimental data. The continued rise of ozone concentration until $t=5 \mathrm{~min}$ recorded during the experiments, combined with the CFD findings, support the hypothesis that ozone emission from the device is not immediately stopped when the production phase is halted.

\subsection{Role of production and decay rates}

Finally, a specific focus is placed upon the ozone concentration response under the influence of lower production rates (between $4.7 \mathrm{~g} / \mathrm{h}$ and $7 \mathrm{~g} / \mathrm{h}$ ) 

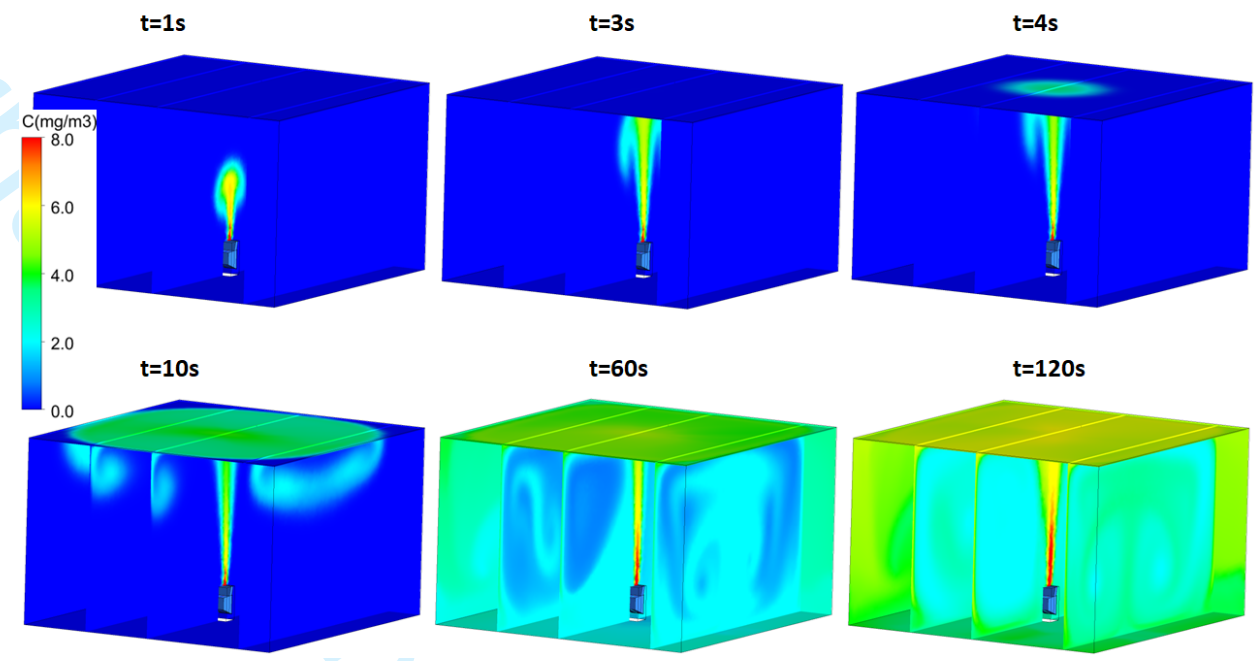

$t=180 s$
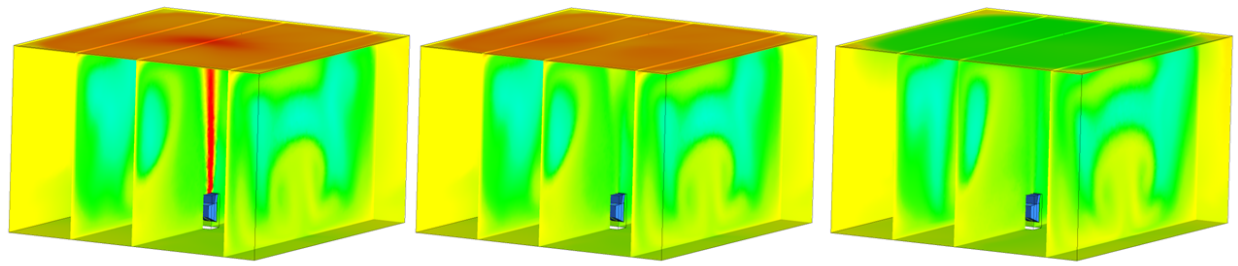

$t=210 s$
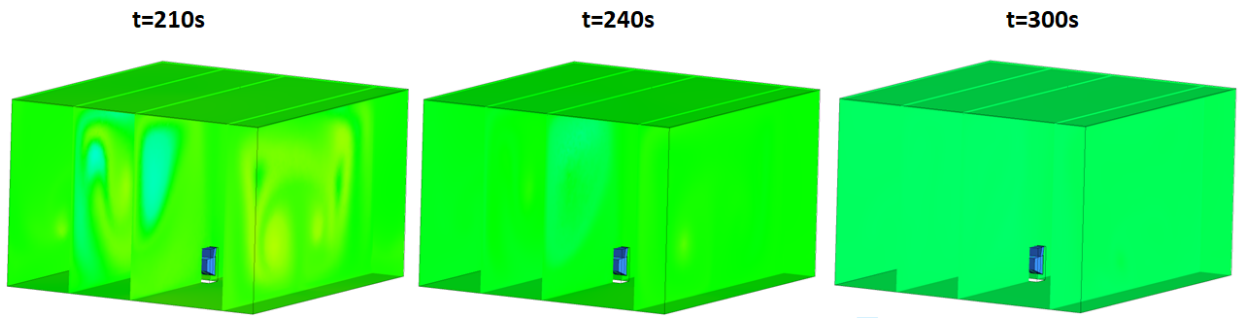

Figure 3: Ozone concentration fields, transient solutions, generation time: 3 min, followed by dwell time: $2 \mathrm{~min}$. O3 production rate: $7 \mathrm{~g} / \mathrm{h}$.

and decay kinetics (between $k=0$ and $k=0.15 \mathrm{~min}^{-1}$ ) during the generation time (first $3 \mathrm{~min}$ ). The overall impact of production rates and decay rates on concentration distribution for two locations inside the room (Channel 1 - Back right corner (floor), and Channel 2 - Wall) are presented in Figure 4. Three different production rates $(4.7 \mathrm{~g} / \mathrm{h}, 6 \mathrm{~g} / \mathrm{h}$, and $7 \mathrm{~g} / \mathrm{h})$ are considered (Figure 4 a,c). As expected, a rising trend in ozone concentration is observed for an increased production rate. With a production rate increase from $(4.7 \mathrm{~g} / \mathrm{h}$ down to $7 \mathrm{~g} / \mathrm{h})$, there are approximately $34 \%$ and $36 \%$ increase in ozone concentration levels at $t=3 \mathrm{~min}$ on Channel 1 and Channel 2 respectively. Remarkably, there are no significant changes in ozone concentration before $1.5 \mathrm{~min}$ with increasing decay rates at back right corner of the 


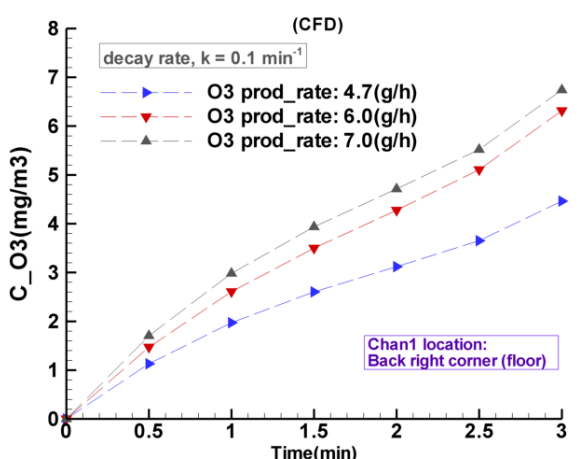

(a)

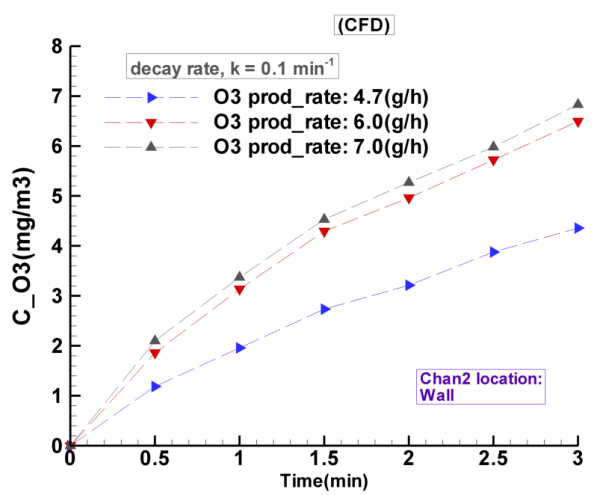

(c)

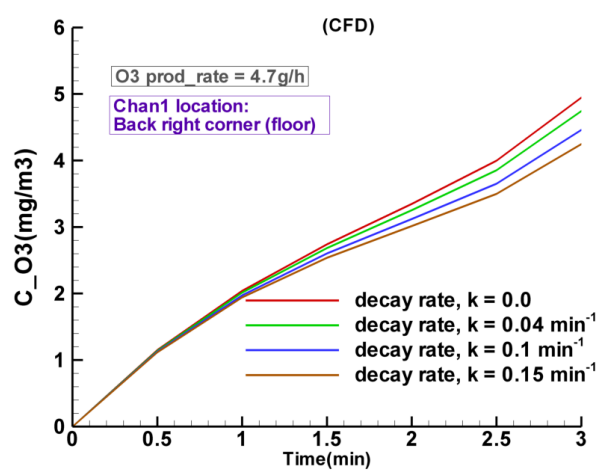

(b)

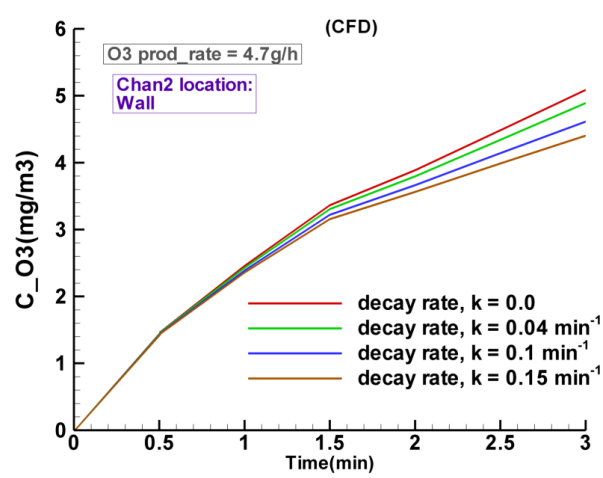

(d)

Figure 4: CFD solution of ozone concentration at different locations for different production and decay rates.

room and wall (Figure $4 \mathrm{~b}, \mathrm{~d}$ ). However, after $2 \mathrm{~min}$ it is possible to observe that the level of ozone concentration decreases for higher decay rates. Here, almost $14 \%$ decrease in ozone concentration is recorded at $t=3 \mathrm{~min}$ as the decay rate is increased from $k=0$ to $k=0.15 \mathrm{~min}^{-1}$. This difference can be ascribed to the first order decay model, which is itself dependent on the concentration, and therefore leading to a more pronounced effect as ozone concentration rises.

\section{Conclusions}

In this preliminary study, a computational methodology describing solute transport by turbulent flow is used for predicting how the level of ozone concentration within a closed room varies during a Covid-19 disinfection process. For the 15 min time interval of the cleaning intervention, the numerical results are in good agreement with the experimental measurements. This comparison proves that the presented methodology is able to 
provide accurate predictions of the time evolution of solute concentration at different locations of the enclosed space.

This work can provide a solid base for future studies. In order to have a better distribution of the gas within the room, one could evaluate the effect of changing the location of the fan/generator in the room and identify the best position for reaching a certain value of solute concentration everywhere within the shortest time. Furthermore, this computational framework can also guide in the design of future experimental studies. The same methodology could be also used for modelling solute transport in closed rooms having a much more complex furniture arrangement with the fan placed at different locations. Other relevant elements that could be considered in future studies are the levels of humidity and temperature distributions in the room. For a comprehensive safety analysis of the O3-based procedure, also the formation of Volatile Organic Compounds (VOCs) could be accounted for. Given its potential importance, future studies are necessary for evaluating the impact of this phenomenon on the disinfection process. Finally, it is important to say that the current methodology can find application in a very broad spectrum of sectors: from public transports, including airline and railway networks, to different types of buildings, including residential, commercial and public structures.

\section{Acknowledgements}

Authors acknowledge the financial support received from the Welsh Government under the Collaborative Research and Innovation Support Programme (CRISP20-001) and the Ser Cymru III - Tackling Covid 19 fund (Project number 095). We thank the ASTUTE2020 project for allowing access to Fluent software and the SPECIFIC Innovation and Knowledge Centre at Swansea University for facilitating the experimental work in the Active Office building.

\section{References}

[1] Lidia Morawska and D.K. Milton. It Is Time to Address Airborne Transmission of Coronavirus Disease 2019 (COVID-19). Clinical Infectious Diseases, 71(9):2311-2313, 2020.

[2] Neeltje Van Doremalen, Trenton Bushmaker, Dylan H Morris, Myndi G Holbrook, Amandine Gamble, Brandi N Williamson, Azaibi Tamin, Jennifer L Harcourt, Natalie J Thornburg, Susan I Gerber, et al. Aerosol and surface stability of SARS-CoV-2 as compared with SARSCoV-1. New England Journal of Medicine, 382(16):1564-1567, 2020.

[3] Mahmood Alimohammadi and Maziar Naderi. Effectiveness of ozone gas on airborne virus inactivation in enclosed spaces: A review study. Ozone: Science \& Engineering, pages 1-11, 2020. 
[4] Chedly Tizaoui. Ozone: A Potential Oxidant for COVID-19 Virus (SARS-CoV-2). Ozone: Science \& Engineering, 42(5):378-385, 2020.

[5] Chunchieh Tseng and Chihshan Li. Inactivation of surface viruses by gaseous ozone. Journal of environmental health, 70(10):56-63, 2008.

[6] Xu-Qin Jiang, Xiao-Dong Mei, and Di Feng. Air pollution and chronic airway diseases: what should people know and do? Journal of thoracic disease, 8(1):E31, 2016.

[7] Ramon Codina, Christopher Morton, Eugenio Onate, and Orlando Soto. Numerical aerodynamic analysis of large buildings using a finite element model with application to a telescope building. International Journal of Numerical Methods for Heat \& Fluid Flow, 10(6):613-633, 2000.

[8] Souad Morsli, Mustapha Boussoufi, Amina Sabeur, Mohammed El Ganaoui, and Rachid Bennacer. Small to large scale mixed turbulent convection: buildings application. International Journal of Numerical Methods for Heat \& Fluid Flow, 28(1):188-205, 2018.

[9] Zohir Younsi, Lounes Koufi, and Hassane Naji. Numerical study of the effects of ventilated cavities outlet location on thermal comfort and air quality. International Journal of Numerical Methods for Heat E Fluid Flow, 29(11):4462-4483, 2019.

[10] Vinh Van Tran, Duckshin Park, and Young-Chul Lee. Indoor air pollution, related human diseases, and recent trends in the control and improvement of indoor air quality. International Journal of Environmental Research and Public Health, 17(8):2927, 2020.

[11] Ioannis Manisalidis, Elisavet Stavropoulou, Agathangelos Stavropoulos, and Eugenia Bezirtzoglou. Environmental and health impacts of air pollution: A review. Frontiers in public health, 8, 2020.

[12] Zhibo Shi, Jie Bai, and Yong Han. Distribution of ozone and its volatiles in indoor environment: a numerical simulation with cfd for the aircraft cabin. Environmental Technology, 41(24):3146-3156, 2020.

[13] World Health Organization et al. Who air quality guidelines for particulate matter, ozone, nitrogen dioxide and sulfur dioxide: global update 2005: summary of risk assessment. Technical report, World Health Organization, 2006.

[14] Heidi Salonen, Tunga Salthammer, and Lidia Morawska. Human exposure to ozone in school and office indoor environments. Environment international, 119:503-514, 2018. 
[15] Charles J Weschler. Ozone in indoor environments: concentration and chemistry. Indoor air, 10(4):269-288, 2000.

[16] M. A. Khadre, A. E. Yousef, and J.-G. Kim. Microbiological aspects of ozone applications in food: a review. Journal of food science, 66(9):1242-1252, 2001.

[17] J. D. McClurkin and D. E. Maier. Half-life time of ozone as a function of air conditions and movement. Julius-Kühn-Archiv, (425):381, 2010.

[18] Perumal Nithiarasu, Roland W. Lewis, and Kankanhalli N. Seetharamu. Fundamentals of the finite element method for heat and mass transfer. John Wiley \& Sons, 2016.

[19] Philippe Spalart and Steven Allmaras. A one-equation turbulence model for aerodynamic flows. In 30th aerospace sciences meeting and exhibit, page 439, 1992.

[20] Steven R Allmaras and Forrester T Johnson. Modifications and clarifications for the implementation of the spalart-allmaras turbulence model. In Seventh international conference on computational fluid $d y$ namics (ICCFD'), pages 1-11, 2012.

[21] P. Nithiarasu and C. B. Liu. An artificial compressibility based characteristic based split (cbs) scheme for steady and unsteady turbulent incompressible flows. Computer Methods in Applied Mechanics and Engineering, 195(23-24):2961-2982, 2006.

[22] C. Hirsch. Numerical Computation of Internal and External Flows, volume 1. John Wiley \& Sons, New York, 1992.

[23] D. Yang and Z. Gao. A linearity-preserving vertex interpolation algorithm for cell-centered finite volume approximations of anisotropic diffusion problems. International Journal of Numerical Methods for Heat \& Fluid Flow, 30(3):1167-1188, 2019.

[24] Elena Grignani, Antonella Mansi, Renato Cabella, Paola Castellano, Angelo Tirabasso, Renata Sisto, Mariangela Spagnoli, Giovanni Fabrizi, Francesco Frigerio, and Giovanna Tranfo. Safe and Effective Use of Ozone as Air and Surface Disinfectant in the Conjuncture of Covid-19. Gases, 1(1):19-32, 2021. 


\title{
Modelling Ozone Disinfection Process for Creating Covid-19 Secure Spaces
}

\begin{abstract}
Purpose

A novel modelling approach is proposed to study ozone distribution and destruction in indoor spaces. The level of ozone gas concentration in the air, confined within an indoor space during an ozone-based disinfection process, is analysed. The main purpose of this work is to investigate how ozone is distributed in time within an enclosed space.
\end{abstract}

\section{Design/methodology/approach}

A computational methodology for predicting the space and time dependent ozone concentration within the room across the consecutive steps of the disinfection process (generation, dwelling and destruction modes) is proposed. The emission and removal of ozone from the air volume are possible by means of a generator located in the middle of the room. This model also accounts for ozone reactions and decay kinetics, and gravity effect on the air.

\section{Finding}

This work is validated against experimental measurements at different locations in the room during the disinfection cycle. The numerical results are in good agreement with the experimental data. This comparison proves that the presented methodology is able to provide accurate predictions of the time evolution of ozone concentration at different locations of the enclosed space.

\section{Originality/value}

This study introduces a novel computational methodology describing solute transport by turbulent flow for predicting the level of ozone concentration within a closed room during a Covid-19 disinfection process. A parametric study is carried out to evaluate the impact of system settings on the time variation of ozone concentration within the space considered.

Keywords: Ozone disinfection, Covid-19, Ozone decay rate, Concentration distribution, Unsteady Reynolds Average Navier-Stokes, Scalar transport equation 


\section{Introduction}

The Covid-19 outbreak has increased awareness of transmission mechanisms of respiratory diseases, especially in indoor environments. Respiratory viruses spread via direct or indirect contact, droplet and aerosol transmission. Evidence [1, 2] suggests that the virus is quickly released during exhalation, talking, and coughing in microdroplets small enough to remain aloft in the air and on surfaces for days, exposing the surrounding people to high infection risk. Therefore, there is an urgent need for a reliable and efficient disinfection method to decontaminate these high-risk areas. The Covid-19 pandemic has boosted the number of studies on ozone disinfection methods for indoor spaces 3. Ozone is a powerful oxidiser, and an ideal disinfectant, which is effective in killing a wide variety of bacteria and viruses [4, 5]. However, human exposure to ozone can be the cause of several health problems, including coughing, breathing difficulty, and lung damage [6]. Thus, safety considerations should be given full review, i.e., all traces of ozone should be eliminated from indoor space before human occupation. While several experimental works have been carried out to understand the safety and efficacy of ozone as a decontaminator, it is also extremely important defining reliable modelling methodologies for making predictions and optimising the cleaning process. Thus, in the present work, we use computational fluid dynamics (CFD) modelling for analysing the ozone concentration distribution in indoor environments.

In the last decades, evaluation of fluid dynamics patterns in indoor environment environments has been an area under intense investigation [7 9 ]. Likewise, the analysis of how pollution and biological agents can spread within an indoor environment has received continuous attention from the research community [10 12]. Combining such studies to understand the ozone generation, spread and destruction using CFD may provide a better understanding of decontamination issues and allow us to optimise this process. Through the present work, the ozone distribution is modelled in the room air volume and evaluated at each stage of an ozone-based disinfection cycle. Furthermore, by considering such time-frame, we characterise the ozone residence time. This is a key information for assessing the health and the safety conditions associated with the disinfection process [13, 14]. Under normal conditions, the half-life of ozone in indoors is between 7 and $30 \mathrm{~min}$ and is determined primarily by surface removal and air exchange [15 17. However, for inferring the ozone lifespan in a complex environment characterized by continuously-changing flow conditions, a high fidelity modelling approach is required.

This study aims to introduce a novel computational methodology able to accurately predict, for a given generator setting, how ozone is distributed in time within an enclosed space considered. Furthermore, this methodology is employed for identifying the optimal time required for effectively 
disinfecting a room by considering various ozone production rates and destruction rates. This paper is organised as follows: Section 2 provides the details on the adopted computational methodology. The description of the problem considered, and the associated experimental setup is reported in Section 3. This is followed by Section 4 in which the results are reported. In the last section, the significant findings of the study are summarised, and recommendations for future studies are made.

\section{Modelling Method}

The forced air circulation within a room may be described by employing turbulent incompressible flow equations, whilst the distribution of ozone concentration in the air may be modelled via the convection-diffusion equation. These equations and their solution method are briefly summarised in this section.

\subsection{Air flow}

The incompressible Navier-Stokes equations, governing time averaged turbulent flow, in dimensional form consists respectively of the mass conservation and the momentum conservation equations, i.e,

$$
\begin{aligned}
& \nabla \boldsymbol{v}=0 \\
& \text { and } \\
& \rho \frac{\partial \boldsymbol{v}}{\partial t}=-\rho(\boldsymbol{v} \nabla) \boldsymbol{v}-\nabla p+(\nu+\hat{\nu}) \nabla^{2} \boldsymbol{v}+\boldsymbol{F}
\end{aligned}
$$

where $\rho$ is the air density, $\boldsymbol{v}$ is the velocity, $p$ is the pressure, $\nu$ is the kinematic viscosity and $\hat{\nu}$ is the turbulent eddy viscosity. Buoyancy-driven mass convection along the vertical direction is generated by the density difference, which is induced by the concentration gradient $C-C_{\infty}$, in which $C_{\infty}$ is the reference concentration (assumed to be 0 in this study) [18. $\boldsymbol{F}$ is a source term formulated to account for buoyancy:

$$
\boldsymbol{F}=\mathrm{g} \beta_{\mathrm{c}}\left(C-C_{\infty}\right) \hat{\boldsymbol{y}}
$$

in which $\hat{\boldsymbol{y}}$ is the unit vector in the vertical direction, $\mathrm{g}$ is the acceleration due to gravity $\left(9.81 \mathrm{~m} / \mathrm{s}^{2}\right), \beta_{c}$ is the coefficient of solutal expansion, assumed to be of order $\mathrm{O}\left(10^{-3}\right)$.

\subsection{Turbulence}

The one equation Spalart-Allmaras (SA) model is employed here for calculating the turbulent eddy viscosity [19 21]. The SA model employs a 
single scalar equation and several constants to model turbulence. The scalar equation is:

$$
\begin{gathered}
\frac{\partial \hat{\nu}}{\partial t}+\frac{\partial u_{j} \hat{\nu}}{\partial x_{j}}=c_{b 1} \hat{S} \hat{\nu}+\frac{1}{\sigma}\left[\frac{\partial}{\partial x_{i}}(\nu+\hat{\nu}) \frac{\partial \hat{\nu}}{\partial x_{i}}+c_{b 2}\left(\frac{\partial \hat{\nu}}{\partial x_{i}}\right)^{2}\right]-c_{w 1} f_{w}\left[\frac{\hat{\nu}}{y}\right]^{2} \\
\text { where } \hat{S}=S+\left(\hat{\nu} / k^{2} y^{2}\right) f_{v 2} \\
f_{v 2}=1-X /\left(1+X f_{v 1}\right)
\end{gathered}
$$

In Equation $5 S$ is the magnitude of vorticity. The eddy viscosity is calculated as:

$$
\nu_{t}=\hat{\nu} f_{v 1}
$$

where,

$$
f_{v 1}=X^{3} /\left(X^{3}+c_{v 1}^{3}\right)
$$

and

$$
X=\hat{\nu} / \nu
$$

The parameter $f_{w}$ is given as:

$$
f_{w}=g\left[\frac{1+c_{w 3}^{6}}{g^{6}+c_{w 3}^{3}}\right]^{1 / 6}
$$

where,

$$
g=r+c_{w 2}\left(r^{6}-r\right)
$$

and

$$
r=\frac{\hat{\nu}}{\hat{S} k^{2} y^{2}} .
$$

The constants are $c_{b 1}=0.1355, \sigma=2 / 3, c_{b 2}=0.622, k=0.41, c_{w 1}=$ $c_{b 1} / k^{2}+\left(1+c_{b 2}\right) / \sigma, c_{w 2}=0.3, c_{w 3}=2$ and $c_{v 1}=7.1$. 


\subsection{Ozone Transport}

The turbulent convection-diffusion equation for evaluating the ozone concentration in space and time may be written as:

$$
\rho \frac{\partial C}{\partial t}=-\rho(\boldsymbol{v} \nabla) C+\rho\left[\frac{\nu}{S c}+\frac{\hat{\nu}}{S c_{t}}\right] \nabla^{2} C+[S-k C],
$$

where $C$ is the ozone volumetric concentration in the air, $S$ is the ozone source, $S c$ and $S c_{t}$ are the Schmidt numbers (assume to be unity) and $k$ is the ozone decay and reaction coefficient. Here it is assumed that the natural ozone decay follows a kinetics represented by a first-order reaction, characterised by the decay constant $k$. The same assumption is made for ozone destruction occurring on the selective surfaces of the built-in ozone destructor, which is part of the ozone system, and this latter effect is included by simply using an appropriate high value of the decay constant $k$ (for the nodes on the surface). It is worth mentioning that whilst the natural decay is a volumetric effect, the destruction occurs only on the surface of the generator when the destruction mode is active.

Computer simulations are performed with a CFD solver based on the finite volume method using a Cell-Centered formulation 22,23$]$. The flow distribution in space obtained by solving Equations 1, 2 and 4 are coupled with the concentration distribution of ozone obtained by solving Equation 13. The concentration calculations follow the following consecutive steps: i) ozone generation via source term and concentration distribution in air, ii) dwell time where both ozone generation and destruction are off and iii) ozone destruction, dominated by ozone reactions occurring at the surface of the catalytic ozone destructor, which is integrated in the ozone system. More details about how to model these effects are reported in the following section.

\section{Problem specification}

In this work, an ozone system is placed at the middle of a $47 \mathrm{~m}^{3}$ room $4.0 \mathrm{~m}$ by $4.3 \mathrm{~m}$, and $2.7 \mathrm{~m}$ high. The generator includes the ozone generation system, the destructor, and a fan to blow air; all are integrated in one unit (Figure 1). A mechanical gate is used to divert the direction of air flow from vertical, during ozone generation, to horizontal, during ozone decay. The ozone system uses a catalytic destructor to convert ozone back to oxygen once the sterilisation mode is completed to make the room safe for occupation again. Each of these modes uses a shared inlet to the device but employ different outlet (Figure 1). In generation mode, the air flow rate is $335 \mathrm{~m}^{3} / \mathrm{h}$ induced by a fan pressure rise of $75 \mathrm{~Pa}$ from the inlet $\left(0.028 \mathrm{~m}^{2}\right)$, to the ozone generation outlet $\left(0.0158 \mathrm{~m}^{2}\right)$ of the device. The ozone generation rate is $7 \mathrm{~g} / \mathrm{h}$. 

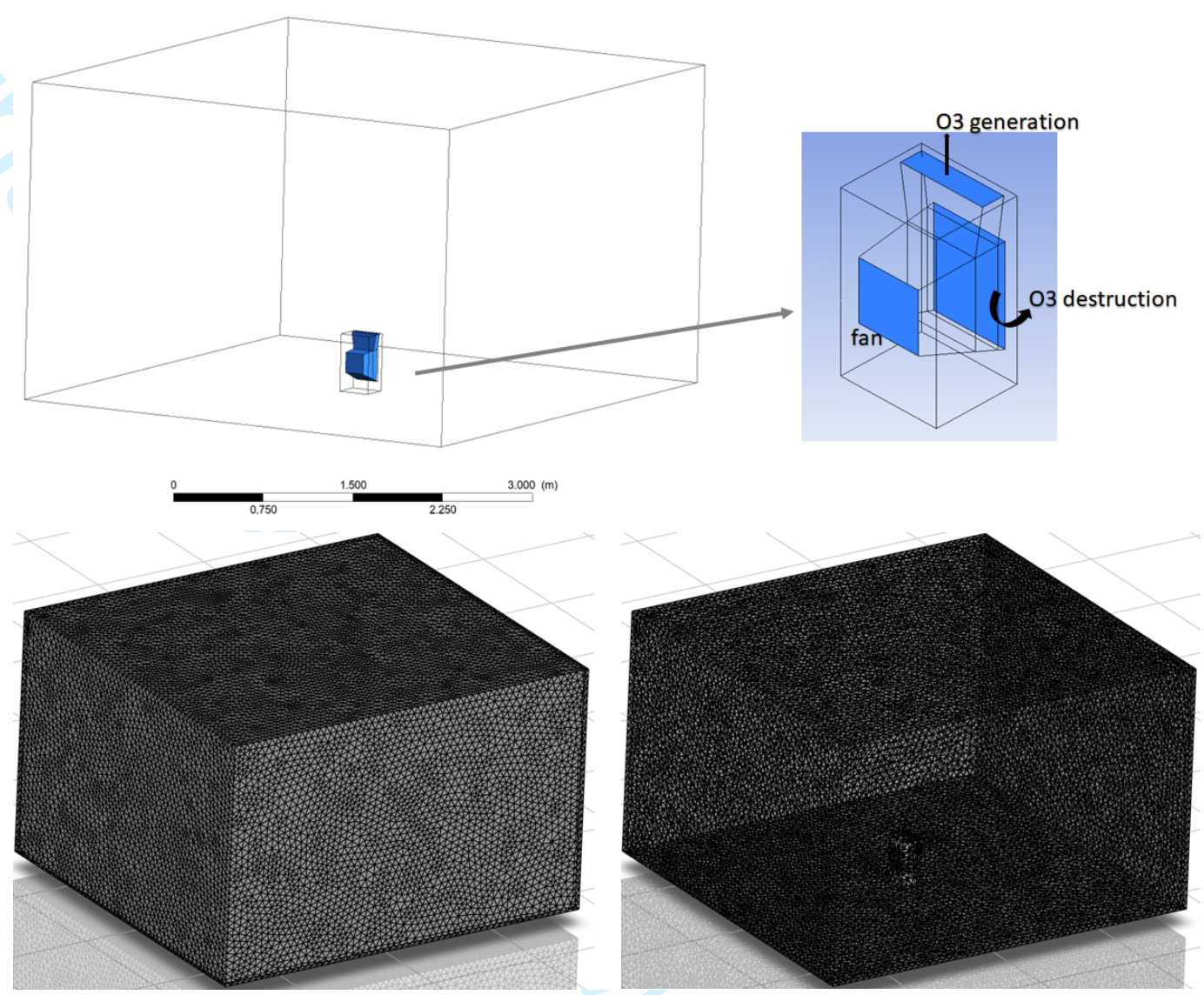

Figure 1: Schematic of model room with zoomed ozone generator and corresponding mesh $(1,139,951$ cells $)$ with the front faces transparent.

In destruction mode, the air flow and ozone destruction rates are $295 \mathrm{~m}^{3} / \mathrm{h}$ induced by a fan pressure rise of $10 \mathrm{~Pa}$ from the inlet $\left(0.028 \mathrm{~m}^{2}\right)$ to the ozone destruction outlet $\left(0.054 \mathrm{~m}^{2}\right)$ of the device. The ozone decay is linked to concentration with a decay constant $k=0.1 \mathrm{~min}^{-1}$. The ozone diffusion coefficient in Equation 13 is $D=3.1116 \cdot 10^{-5} \mathrm{~kg} \mathrm{~m}^{-1} \mathrm{~s}^{-1}$.

The sterilisation cycle modelled consists of three steps. The first is ozone generation and circulation. The second step is a dwell time where ozone is neither generated nor destroyed, but the fan is maintained in generation regime to circulate air. In the final step, the ozone destruction mode is enabled. Several time sequences are tested and explained in the validation section.

\subsection{CFD Solver}

The simulations were carried out using Ansys Fluent on 40 processors with the Intel MPI. The simulations use a scalar transport model for ozone, 
rather than a multi-phase approach which enables the use of the pressurecoupled algorithm. In the spatial domain, gradients are discretised using the cell-based least square algorithm. A second order discretisation is used for the pressure field, and a second order upwind scheme is used for momentum equation. Turbulent viscosity and ozone concentration are both discretised with a first order upwind scheme. The time stepping is done using a first order implicit scheme. A fixed time step of $0.1 \mathrm{~s}$ was employed, whilst the mesh used to represent the system's geometry consists of $1,139,951$ cells. Since interest here is ozone concentration, not derivatives, further mesh refinement did not introduce any significant change in concentration distribution.

\subsection{Experimental setup}

A Duo20 ozone generator (Advanced Ozone Products, UK) was used to ozonate an empty room $(4.0 \mathrm{~m} \times 4.3 \mathrm{~m} \times 2.7 \mathrm{~m})$. The Duo20 was placed in the centre of the room (on the floor) and set for a 15 min ozone cycle ( $3 \mathrm{~min}$ of ozone generation time, 2 min dwell time and 10 min ozone destruction time). Ozone concentration was then measured using a six-channel BMT 932 ozone monitor (BMT Messtechnik, Germany). The BMT 932 ozone monitor is able to monitor ozone concentration through 5 channels placed within the room (Channel 6 was placed outside the room for safety purposes) by measuring the UV absorbance at $254 \mathrm{~nm}$. Samples were collected using $3 \mathrm{~m}$ length FEP tubes fixed at different points of the room. The 3-D space coordinates of each point from a reference point were measured using a laser distance measuring meter. The ozone monitor measured ozone concentration at each channel in a sequence mode. The cycle time was $20 \mathrm{~s}$ per sample channel and the room conditions were $1 \mathrm{~atm}$ and $20^{\circ} \mathrm{C}$. Note that, the production rate as determined by the measurements obtained from the channels are found to be around $7 \mathrm{~g} / \mathrm{h}$.

\section{Results and Discussion}

\subsection{Comparison with experimental data}

Here the simulation results are compared against the experimental data recorded at four different locations (coordinates, in metres):

- Channel 1 - Back right corner (floor) $(3.937,4.296,0)$;

- Channel 2 - Wall (1.091, 4.356, 0.959);

- Channel 3 - Front left corner (floor) $(0.04,0.04,0)$

- Channel 4 - On light fixture $(2.356,3.214,2.210)$. 
In Figure 2, three different simulated ozone concentration profiles are displayed for each sensor location, as well as the experimental results: one case presenting $5 \mathrm{~min}$ generation time (no dwell time, i.e. ozone generation off and destruction off), second one with 4 min generation time (1 min dwell time), and third one with 3 min generation time (2 min dwell time). The destruction time of all the simulations is conducted for $10 \mathrm{~min}$. According to the manufacturer, the generation time and dwell time are supposed to be $3 \mathrm{~min}$ and $2 \mathrm{~min}$, respectively. However, the real duration of the dwell time is uncertain and potentially affected by different factors, as suggested by the numerical results presented in Figure 2. Thus, 5 min generation without dwell time appears to be a reasonable assumption. The uncertainty arises due to the mechanisms of ozone generation, whereby a sudden shutdown of production is not feasible and thus the device may effectively carry on venting out ozone during the circulation dwell time. This motivated the parametric analysis on generation times and production rates presented in the next sections.

The general trends of the results shown in Figure 2 indicate that at all sensor locations, the ozone concentration inside the room rises rapidly, and then it suddenly drops once the ozone generator is off. For instance, the experimental measurement at back right corner of the room (Channel 1) shows a maximum level of ozone concentration of $10.56 \mathrm{mg} / \mathrm{m}^{3}$ after around $4.4 \mathrm{~min}$ and a lower value of $3.48 \mathrm{mg} / \mathrm{m}^{3}$ (almost 3 times drop compared to the maximum value) at $t=14.97 \mathrm{~min}$, see Figure 2 a. The CFD counterpart shows a maximum level of ozone concentration of $9.32 \mathrm{mg} / \mathrm{m}^{3}$ at $t=5 \mathrm{~min}$ for the $5 \mathrm{~min}$ generation time (no dwell time) scenario, whilst the maximum level of ozone concentration with 4 min generation time (1 $\mathrm{min}$ dwell time) and $3 \mathrm{~min}$ generation time ( $2 \mathrm{~min}$ dwell time) are $8.22 \mathrm{mg} / \mathrm{m}^{3}$ and $6.94 \mathrm{mg} / \mathrm{m}^{3}$, respectively. In addition, the time evolution of the experimentally recorded ozone concentration at Channel 2 (wall, Figure $2 \mathrm{~b}$ ) and Channel 3 (front left corner of the room, Figure 22) are in good agreement with the numerical results corresponding to a generation time of $5 \mathrm{~min}$ (no dwell time). However, the CFD results corresponding to 4 and 3 min of generation time underestimate the concentration measured at Channel 2 and Channel 3. A similar pattern is also observed for the data corresponding to Channel 4 (see Figure 20 d).

It is important to report that, in our experiment, an average ozone concentration value of around $0.26 \mathrm{mg} / \mathrm{m}^{3}$ is recorded by Channels $1-4$ at $t=80 \mathrm{~min}$. This value drops to $0.16 \mathrm{mg} / \mathrm{m}^{3}$ at $t=85 \mathrm{~min}$. This is in line with the guidelines provided by the National Institute for Occupational Safety and Health (NIOSH), which has recently set [24].

Furthermore, transient solutions of ozone concentration distribution fields are presented in Figure 3 for the generation time over the first $3 \mathrm{~min}$, and subsequent dwell time of $2 \mathrm{~min}$. The sudden sharp drop in ozone concentration is evident at the start of the dwell time (from $t=3 \mathrm{~min}$ ). This is also 


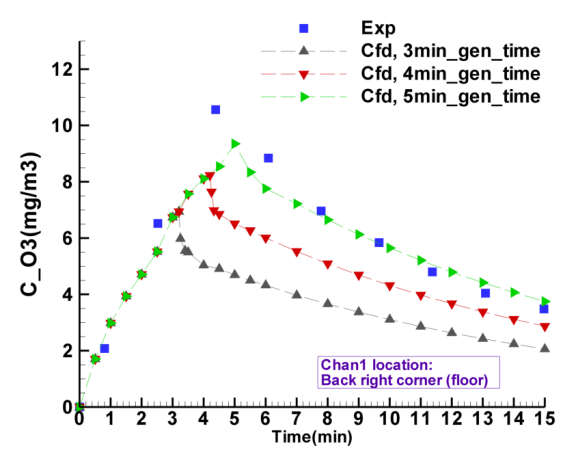

(a)

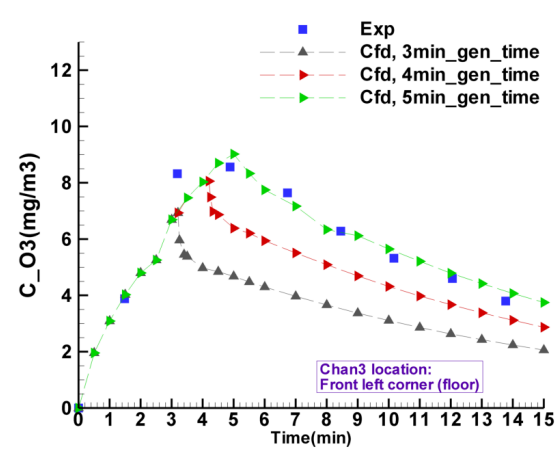

(c)

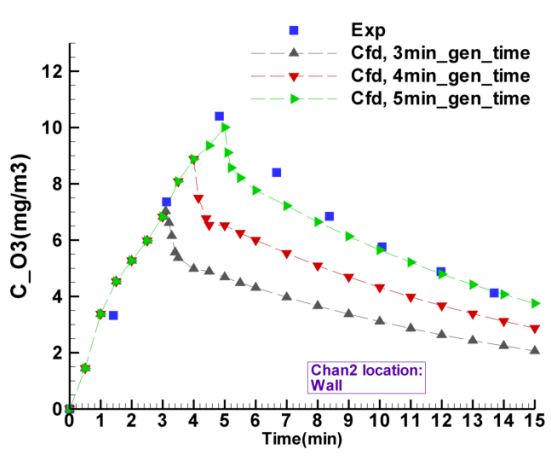

(b)

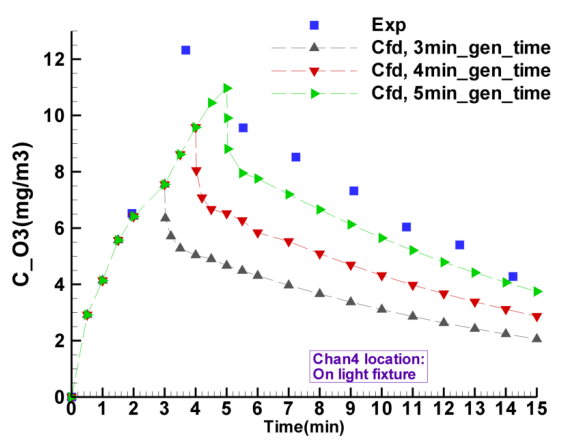

(d)

Figure 2: Comparison between experimental data against CFD results at different locations with different ozone generation times. O3 production rate: $7 \mathrm{~g} / \mathrm{h}$.

evident in Figure 2 for the 3 min generation time case. It is reasonable that at the end of the generation phase higher concentrations are present along the ceiling, wall and floor. This is quickly homogenised in the ventilated dwell phase, resulting in a concentration drop along the walls, where sensors are located. This causes the sharp drop at the end of the ozone production phase. Sensor 3 reports lower concentrations, correctly reproduced in simulations, due to its corner location receiving limited ventilation.

The use of nominal production rates and flow rates from the device in the CFD calculations shows a concentration rise at the locations of measurement and agrees well with the experimental data. The continued rise of ozone concentration until $t=5 \mathrm{~min}$ recorded during the experiments, combined with the CFD findings, support the hypothesis that ozone emission from the device is not immediately stopped when the production phase is halted.

\subsection{Role of production and decay rates}

Finally, a specific focus is placed upon the ozone concentration response under the influence of lower production rates (between $4.7 \mathrm{~g} / \mathrm{h}$ and $7 \mathrm{~g} / \mathrm{h}$ ) 

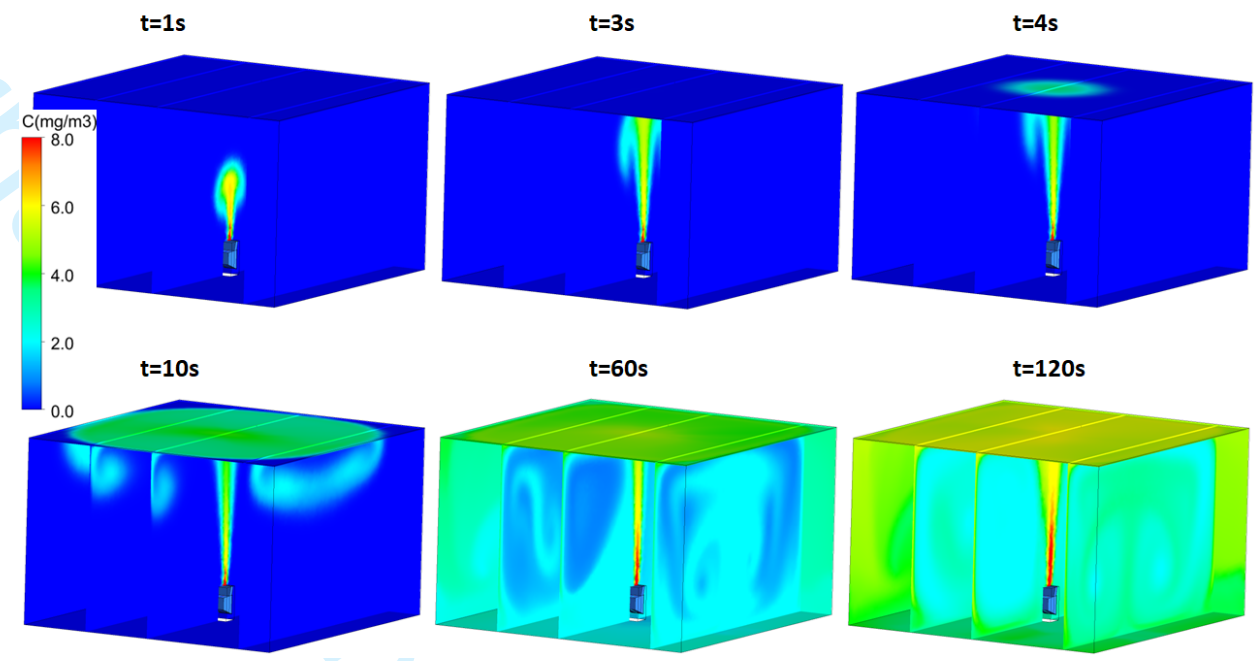

$t=180 s$
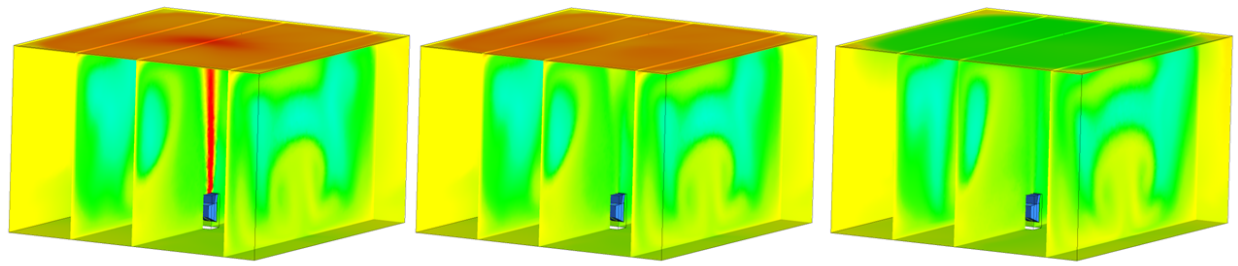

$t=210 s$
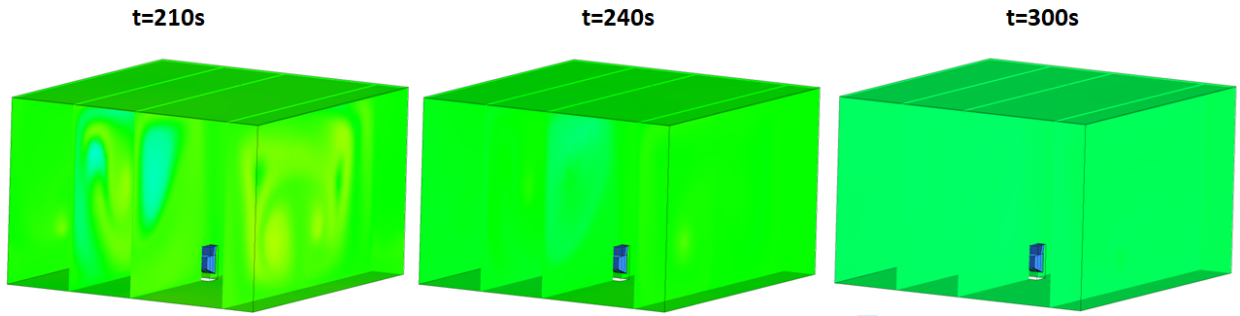

Figure 3: Ozone concentration fields, transient solutions, generation time: 3 min, followed by dwell time: $2 \mathrm{~min}$. O3 production rate: $7 \mathrm{~g} / \mathrm{h}$.

and decay kinetics (between $k=0$ and $k=0.15 \mathrm{~min}^{-1}$ ) during the generation time (first $3 \mathrm{~min}$ ). The overall impact of production rates and decay rates on concentration distribution for two locations inside the room (Channel 1 - Back right corner (floor), and Channel 2 - Wall) are presented in Figure 4. Three different production rates $(4.7 \mathrm{~g} / \mathrm{h}, 6 \mathrm{~g} / \mathrm{h}$, and $7 \mathrm{~g} / \mathrm{h})$ are considered (Figure 4 a,c). As expected, a rising trend in ozone concentration is observed for an increased production rate. With a production rate increase from $(4.7 \mathrm{~g} / \mathrm{h}$ down to $7 \mathrm{~g} / \mathrm{h})$, there are approximately $34 \%$ and $36 \%$ increase in ozone concentration levels at $t=3 \mathrm{~min}$ on Channel 1 and Channel 2 respectively. Remarkably, there are no significant changes in ozone concentration before 1.5 min with increasing decay rates at back right corner of the 


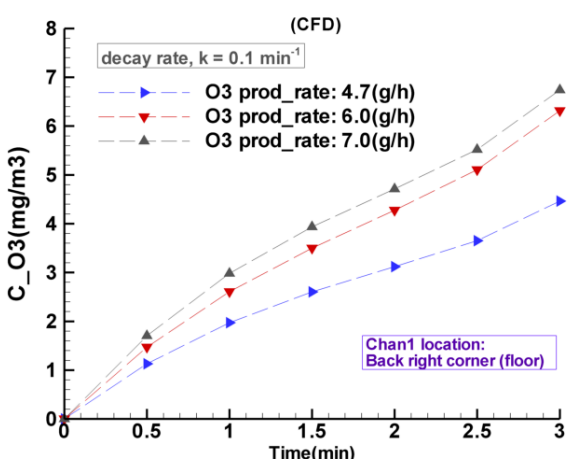

(a)

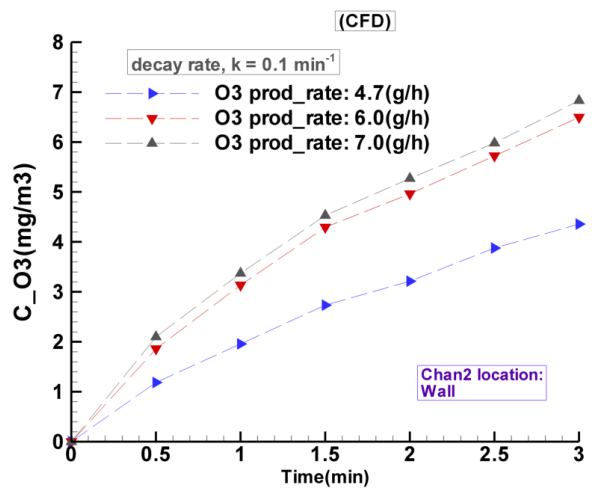

(c)

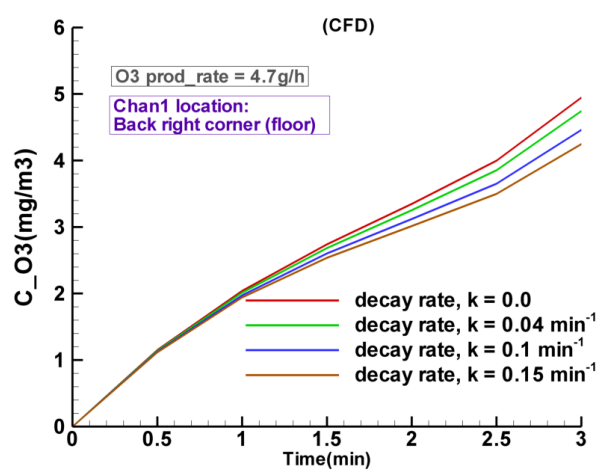

(b)

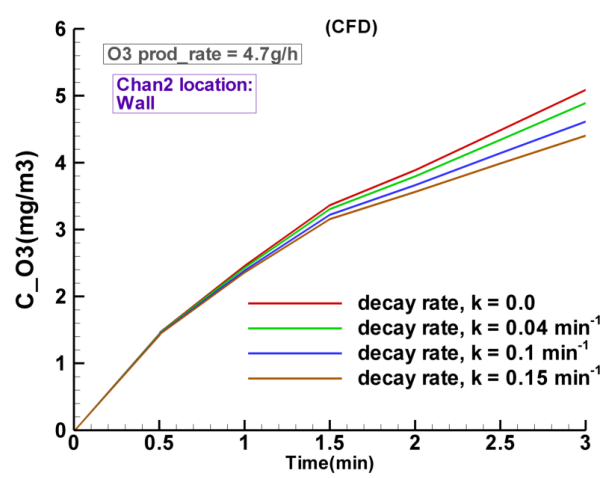

(d)

Figure 4: CFD solution of ozone concentration at different locations for different production and decay rates.

room and wall (Figure $4 \mathrm{~b}, \mathrm{~d}$ ). However, after $2 \mathrm{~min}$ it is possible to observe that the level of ozone concentration decreases for higher decay rates. Here, almost $14 \%$ decrease in ozone concentration is recorded at $t=3 \mathrm{~min}$ as the decay rate is increased from $k=0$ to $k=0.15 \mathrm{~min}^{-1}$. This difference can be ascribed to the first order decay model, which is itself dependent on the concentration, and therefore leading to a more pronounced effect as ozone concentration rises.

\section{Conclusions}

In this preliminary study, a computational methodology describing solute transport by turbulent flow is used for predicting how the level of ozone concentration within a closed room varies during a Covid-19 disinfection process. For the 15 min time interval of the cleaning intervention, the numerical results are in good agreement with the experimental measurements. This comparison proves that the presented methodology is able to 
provide accurate predictions of the time evolution of solute concentration at different locations of the enclosed space.

This work can provide a solid base for future studies. In order to have a better distribution of the gas within the room, one could evaluate the effect of changing the location of the fan/generator in the room and identify the best position for reaching a certain value of solute concentration everywhere within the shortest time. Furthermore, this computational framework can also guide in the design of future experimental studies. The same methodology could be also used for modelling solute transport in closed rooms having a much more complex furniture arrangement with the fan placed at different locations. Other relevant elements that could be considered in future studies are the levels of humidity and temperature distributions in the room. For a comprehensive safety analysis of the O3-based procedure, also the formation of Volatile Organic Compounds (VOCs) could be accounted for. Given its potential importance, future studies are necessary for evaluating the impact of this phenomenon on the disinfection process. Finally, it is important to say that the current methodology can find application in a very broad spectrum of sectors: from public transports, including airline and railway networks, to different types of buildings, including residential, commercial and public structures.

\section{Acknowledgements}

Authors acknowledge the financial support received from the Welsh Government under the Collaborative Research and Innovation Support Programme (CRISP20-001) and the Ser Cymru III - Tackling Covid 19 fund (Project number 095). We thank the ASTUTE2020 project for allowing access to Fluent software and the SPECIFIC Innovation and Knowledge Centre at Swansea University for facilitating the experimental work in the Active Office building.

\section{References}

[1] Lidia Morawska and D.K. Milton. It Is Time to Address Airborne Transmission of Coronavirus Disease 2019 (COVID-19). Clinical Infectious Diseases, 71(9):2311-2313, 2020.

[2] Neeltje Van Doremalen, Trenton Bushmaker, Dylan H Morris, Myndi G Holbrook, Amandine Gamble, Brandi N Williamson, Azaibi Tamin, Jennifer L Harcourt, Natalie J Thornburg, Susan I Gerber, et al. Aerosol and surface stability of SARS-CoV-2 as compared with SARSCoV-1. New England Journal of Medicine, 382(16):1564-1567, 2020.

[3] Mahmood Alimohammadi and Maziar Naderi. Effectiveness of ozone gas on airborne virus inactivation in enclosed spaces: A review study. Ozone: Science \& Engineering, pages 1-11, 2020. 
[4] Chedly Tizaoui. Ozone: A Potential Oxidant for COVID-19 Virus (SARS-CoV-2). Ozone: Science \& Engineering, 42(5):378-385, 2020.

[5] Chunchieh Tseng and Chihshan Li. Inactivation of surface viruses by gaseous ozone. Journal of environmental health, 70(10):56-63, 2008.

[6] Xu-Qin Jiang, Xiao-Dong Mei, and Di Feng. Air pollution and chronic airway diseases: what should people know and do? Journal of thoracic disease, 8(1):E31, 2016.

[7] Ramon Codina, Christopher Morton, Eugenio Onate, and Orlando Soto. Numerical aerodynamic analysis of large buildings using a finite element model with application to a telescope building. International Journal of Numerical Methods for Heat \& Fluid Flow, 10(6):613-633, 2000.

[8] Souad Morsli, Mustapha Boussoufi, Amina Sabeur, Mohammed El Ganaoui, and Rachid Bennacer. Small to large scale mixed turbulent convection: buildings application. International Journal of Numerical Methods for Heat \& Fluid Flow, 28(1):188-205, 2018.

[9] Zohir Younsi, Lounes Koufi, and Hassane Naji. Numerical study of the effects of ventilated cavities outlet location on thermal comfort and air quality. International Journal of Numerical Methods for Heat E Fluid Flow, 29(11):4462-4483, 2019.

[10] Vinh Van Tran, Duckshin Park, and Young-Chul Lee. Indoor air pollution, related human diseases, and recent trends in the control and improvement of indoor air quality. International Journal of Environmental Research and Public Health, 17(8):2927, 2020.

[11] Ioannis Manisalidis, Elisavet Stavropoulou, Agathangelos Stavropoulos, and Eugenia Bezirtzoglou. Environmental and health impacts of air pollution: A review. Frontiers in public health, 8, 2020.

[12] Zhibo Shi, Jie Bai, and Yong Han. Distribution of ozone and its volatiles in indoor environment: a numerical simulation with cfd for the aircraft cabin. Environmental Technology, 41(24):3146-3156, 2020.

[13] World Health Organization et al. Who air quality guidelines for particulate matter, ozone, nitrogen dioxide and sulfur dioxide: global update 2005: summary of risk assessment. Technical report, World Health Organization, 2006.

[14] Heidi Salonen, Tunga Salthammer, and Lidia Morawska. Human exposure to ozone in school and office indoor environments. Environment international, 119:503-514, 2018. 
[15] Charles J Weschler. Ozone in indoor environments: concentration and chemistry. Indoor air, 10(4):269-288, 2000.

[16] M. A. Khadre, A. E. Yousef, and J.-G. Kim. Microbiological aspects of ozone applications in food: a review. Journal of food science, 66(9):1242-1252, 2001.

[17] J. D. McClurkin and D. E. Maier. Half-life time of ozone as a function of air conditions and movement. Julius-Kühn-Archiv, (425):381, 2010.

[18] Perumal Nithiarasu, Roland W. Lewis, and Kankanhalli N. Seetharamu. Fundamentals of the finite element method for heat and mass transfer. John Wiley \& Sons, 2016.

[19] Philippe Spalart and Steven Allmaras. A one-equation turbulence model for aerodynamic flows. In 30th aerospace sciences meeting and exhibit, page 439, 1992.

[20] Steven R Allmaras and Forrester T Johnson. Modifications and clarifications for the implementation of the spalart-allmaras turbulence model. In Seventh international conference on computational fluid $d y$ namics (ICCFD'), pages 1-11, 2012.

[21] P. Nithiarasu and C. B. Liu. An artificial compressibility based characteristic based split (cbs) scheme for steady and unsteady turbulent incompressible flows. Computer Methods in Applied Mechanics and Engineering, 195(23-24):2961-2982, 2006.

[22] C. Hirsch. Numerical Computation of Internal and External Flows, volume 1. John Wiley \& Sons, New York, 1992.

[23] D. Yang and Z. Gao. A linearity-preserving vertex interpolation algorithm for cell-centered finite volume approximations of anisotropic diffusion problems. International Journal of Numerical Methods for Heat \& Fluid Flow, 30(3):1167-1188, 2019.

[24] Elena Grignani, Antonella Mansi, Renato Cabella, Paola Castellano, Angelo Tirabasso, Renata Sisto, Mariangela Spagnoli, Giovanni Fabrizi, Francesco Frigerio, and Giovanna Tranfo. Safe and Effective Use of Ozone as Air and Surface Disinfectant in the Conjuncture of Covid-19. Gases, 1(1):19-32, 2021. 


\title{
Modelling Ozone Disinfection Process for Creating Covid-19 Secure Spaces
}

\author{
H.R. Tamaddon-Jahromi, S. Rolland, J. Jones, A. Coccarelli, I. Sazonov, C.P. Kershaw, C. Tizaoui, P.J. \\ Holliman, D.A. Worsley, H.R. Thomas, P. Nithiarasu \\ Reply to Reviewer 1 :
}

We are extremely grateful for the insightful comments by the reviewer, which have increased the quality of the manuscript. In the revised version of the manuscript the new added text is highlighted in red. We have addressed all the suggestions made by Reviewer 1, and our responses are reported below.

\section{Question1:}

Analysis of Figure 2 states: "The uncertainty arises due to the mechanisms ...... This motivated the study of different simulated generation times." This may be true, but there are other factors that may be occur, as an indication: sensor response time (not specified), thermal environment of the room (which is ignored), mesh and time step (independence study not presented), diffusion coefficient and solutal expansion coefficient (may be the values are underestimated). Please clarify these points.

\section{Answer 1:}

We agree with the reviewer that a clarification regarding the mentioned point is necessary. More information about the equipment and experimental conditions has been included in the text (please see page 7). The added info is summarised below:

- The cycle time was $20 \mathrm{~s}$ per sample channel.

- The room conditions were $1 \mathrm{~atm}$ and $20^{\circ} \mathrm{C}$. The above statements are included in the revised manuscript under experimental setup section 3.2.

- Mesh and time step used for the simulation are now explained in Figure 1 and page 7 of the paper.

- We believe that the ozone diffusion coefficient $\left(3.1116 \times 10^{-5} \mathrm{~kg} \mathrm{~m}^{-1} \mathrm{~s}^{-1}\right)$ is practicable and the solutal expansion of order $\mathrm{O}\left(10^{-3}\right)$ is a reasonable choice.

\section{Question 2:}

It is mentioned: "It is important to report that ........... around $0.2 \mathrm{mg} / \mathrm{m} 3$ is recorded at time t $=80 \mathrm{~min}, \ldots$. continues beyond the $15 \mathrm{~min}$. ." Is this value $(0.2 \mathrm{mg} . \mathrm{m}-3)$ acceptable.

Answer 2:

This statement has been revised in the manuscript on page 8 . The National Institute for Occupational Safety and Health (NIOSH) has set public health air standards of $0.1 \mathrm{ppm}(0.2$ $\mathrm{mg} / \mathrm{m}^{3}$ ) for 8 hours as the limit of the amount of ozone to which people can be safely exposed to.

\section{Question 3:}

Another important point which is not the subject of this study but should be pointed out. This is the reactivity of ozone with air, hazardous chemicals can be formed.

Answer 3:

We agree with the reviewer that the formation of Volatile Organic Compounds (VOCs) as a result of ozone reactions should be included in future safety zone assessments (we are currently looking into this topic in another study). We have now included this consideration in the conclusions.

In conclusion. "...in very good agreement..." changed to "...in good agreement...", as suggested.

New references [16], [17] and [24] with some discussions have been added in the revised version of the manuscript. 